\title{
Mário de Andrade, Francisco Curt Lange e Carleton Sprague Smith as discotecas públicas, o conhecimento musical e a política cultural
}

\author{
Flávia Camargo Toni ${ }^{1}$ e Valquíria Maroti Carozze ${ }^{2}$
}

\section{Resumo}

A proposta deste artigo é, a partir da reunião de focos correlatos de pesquisas, esboçar, no panorama americano dos anos 1930 e 1940, o interesse que tinham o brasileiro Mário de Andrade, o teuto-uruguaio Francisco Curt Lange, e o norte-americano Carleton Sprague Smith no Americanismo musical. Trazendo à luz a correspondência escrita desses três musicólogos e passando pela atuação de Oneyda Alvarenga, visa-se expor a preocupação com a documentação sonora àquela época, em que se enfatizou a criação de discotecas públicas como suporte ao conhecimento musical, na América, bem como lançar um olhar sobre ações de pessoas ligadas a instituições públicas, seus perfis, ora parecidos, ora distantes, seus interesses, ao mesmo tempo comuns e difusos, naquele cenário histórico e político.

\section{Palavras-chave}

Americanismo musical, Mário de Andrade, discotecas, documentação musical, musicologia.

Recebido em 22 de Abril de 2013

Aprovado em 13 de Setembro de 2013

TONI, Flávia Camargo; CAROZZE, Valquiria Maroti. Mário de Andrade, Francisco Curt Lange e Carleton Sprague Smith: as discotecas públicas, o conhecimento musical e a política cultural. Revista do Instituto de Estudos Brasileiros, Brasil, n. 57, p. 181-204, 2013.

DOI: http://dx.doi.org/10.11606/issn.2316-901X.v0i57p181-204

1 Universidade de São Paulo (USP, São Paulo, SP, Brasil).

2 Universidade de São Paulo (USP, São Paulo, SP, Brasil). 


\title{
Mário de Andrade, Francisco Curt Lange and Carleton Sprague Smith Public Disco Collections, Musical Knowledge and Cultural Policy
}

\author{
Flávia Camargo Toni e Valquíria Maroti Carozze
}

\section{Abstract}

The purpose of this article is, from the meeting of outbreaks of related research, sketching, in the American panorama of the 1930s and 1940s, the interest that had the Brazilian Mário de Andrade, the German-Uruguayan Francisco Curt Lange, and the North American Carleton Sprague Smith in the musical Americanism. Bringing to light the written correspondence of these three musicologists and through the action of Oneyda Alvarenga, aims to expose the concern about the sound documentation at that time, which emphasized on the creation of public discotheques as support of musical knowledge, in America, as well as cast an eye on the actions of people associated with public institutions, their profiles, sometimes similar, sometimes distant, their interests, while common and diffuse - in that political and historical setting.

Keywords

Musical amercanism, Mário de Andrade, music libraries, musical documentation, musicology. 


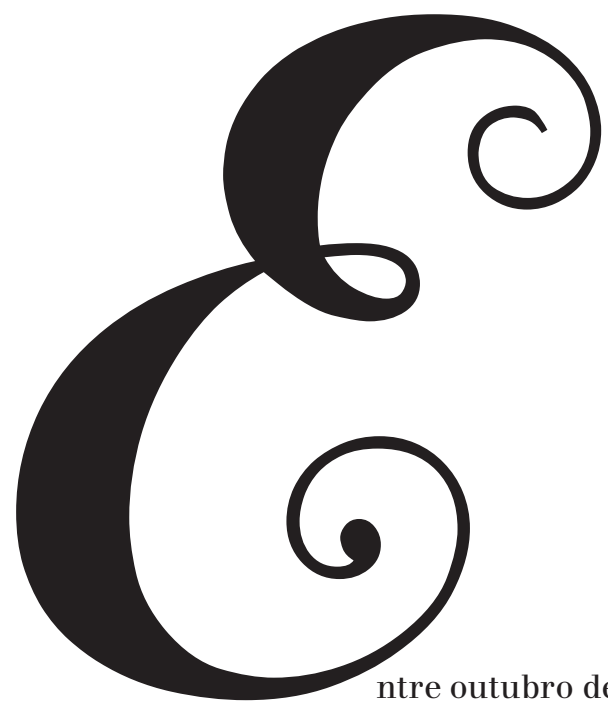

movimento revolucionário e mergulhou imediatamente em outro, tendo Getúlio Vargas como presidente da República. Durante os quinze anos seguintes, Vargas passou de chefe de governo provisório a presidente eleito de forma indireta e, em seguida, a ditador. Durante este tempo também Curt Lange e Sprague Smith se aproximaram de Mário de Andrade. Se o palco das tensões políticas teve como focos as cidades de São Paulo e Rio de Janeiro, por onde todos eles circularam, no microcosmo destaca-se a Discoteca Pública do Departamento de Cultura fundada na gestão do musicólogo paulista. Embora o objetivo deste artigo seja analisar de que forma Mário de Andrade catalisou as diferentes posturas, é importante frisar que na musicologia brasileira ainda não temos muitos trabalhos voltados para a história das instituições ou, mais especificamente, para a história de nossas discotecas. Tampouco se busca trabalhar aqui diretamente com os eixos que tangem as campanhas que moveram os três intelectuais em torno de suas defesas do(s) Nacionalismo(s) e do Americanismo musical. Na presente abordagem, a exploração do tema se limita às possibilidades oferecidas pela correspondència de Mário de Andrade, hoje patrimônio do Instituto de Estudos Brasileiros da Universidade de São Paulo, incluindo dois diálogos epistolares já estudados e anotados: a correspondência de Camargo Guarnieri com Curt Lange foi tema da tese de Cesar Buscacio ${ }^{5}$ e nela há várias menções ao amigo comum; a correspondência do modernista brasileiro com Oneyda Alvarenga foi editada

3 BUSCACIO, Cesar Maia. Americanismo e nacionalismo musicais na correspondência de Curt Lange e Camargo Guarnieri (1934 - 1956). 2009. 275 f. Tese (Doutorado em História Social) - Instituto de Filosofia e Ciências Sociais, Rio de Janeiro, 2009. 
em $1983^{4}$ e também ilumina assuntos pertinentes ao convívio dos três musicólogos 5 .

\section{Mário de Andrade e Francisco Curt Lange trocam cartas}

Intelectual e escritor conhecido, arrastando consigo até a década de 1930 ecos da pecha de poeta futurista (para o bem ou para o mal-entendido), consolidado crítico musical e jornalista, Mário de Andrade foi musicólogo interessado pela criação popular. Por ocasião da fundação e criação do Departamento de Cultura, em 1935, assumiu os cargos de diretor e o de chefe da Divisão de Expansão Cultural. Apesar do ritmo intenso das realizações do Departamento durante a gestão do poeta (1935-1938), a guinada da situação política, com golpe do Estado Novo, em novembro de 1937, leva o escritor a se demitir do cargo de diretor do Departamento, em 1938, sendo substituído por Francisco Pati. Com sua saída da instituição, aceitou o convite para assumir os cargos de catedrático de Filosofia e História da Arte, de diretor no Instituto de Artes da Universidade do Distrito Federal e de consultor técnico do Instituto Nacional do Livro colaborando na programação cultural do Ministério da Educação e Saúde de Gustavo Capanema. Trabalhou também no Serviço do Patrimônio Histórico e Artístico Nacional (SPHAN). Aliás, a rica correspondência trocada com os amigos que permaneceram em São Paulo confirma que ele cumpria papel destacado junto ao ministro Gustavo Capanema, pois a experiência paulistana preparou-o para a política cultural. Logo, era personalidade influente tanto em São Paulo quanto no Rio de Janeiro, as duas cidades por onde Sprague Smith e Curt Lange mais circulariam. Mário de Andrade conheceu Curt Lange em São Paulo na década de 1930, e Sprague Smith no Rio de Janeiro em 1940, poucos meses antes de voltar a São Paulo.

Entre 1932 e 1944 Curt Lange enviou cinquenta cartas ao colega brasileiro, o que, se não constitui uma surpresa - porque é sabido que o musicólogo teuto-uruguaio era de fato um escrevinhador de cartas - pelo menos informa que ele depositava grande expectativa de intercâmbio com o intelectual paulista. Como foi dito, o país começava a fazer um balanço sobre as relações entre as forças políticas que se confrontaram

4 N.E.: Veja também o artigo "Oneyda Alvarenga escreve a Mário de Andrade" de Marilda Ionta publicado nessa mesma revista.

5 Alvarenga, Oneyda; ANDRADE, Mário de. Cartas: Mário de Andrade, Oneyda Alvarenga. São Paulo: Duas Cidades, 1983. 
numa revolução que teve São Paulo como cenário principal, e Lange buscava interlocutores para estabelecer contatos de trabalho.

Nascido em 1903, Curt Lange chegou à América do Sul aos vinte anos de idade com formação em Arquitetura e Música e bem cedo se naturalizou uruguaio. Na primeira carta enviada a Mário de Andrade, o musicólogo apresentou seu currículo:

Soy Profesor en Ciencias musicales, habiendo estudiado en Europa con Nikisch y otros maestros. Actualmente me encuentro al frente de la Discoteca Nacional del Servicio Oficial de Difusión Radio Eléctrica y de la Biblioteca musical de este organismo, habiendo sido llamado por tal causa por el Gobierno del país. A la vez desempeño el cargo de catedrático de Historia estética de la Música en la Universidad. Con esto creo haber hecho la presentación de rigor para que Vd. pueda inmaginarse mis actividades y el motivo de esta carta. ${ }^{6}$

Adiante acrescentou que se dedicava preferentemente ao "terreno científico" com pesquisas sobre Schubert e Beethoven e que, por conta de uma colaboração com Alfred Einstein, editor do Léxico Riemann, começou a fazer um Léxico Sudamericano de la Música. Em pouco tempo Lange percebeu que a Mário de Andrade não interessava realizar um dicionário musical, mesmo porque ele já alimentava o seu próprio projeto. Mas, nas cartas seguintes, pode-se acompanhar o amadurecimento do plano do americanismo musical no qual o musicólogo paulista era peça chave. Eles se conheceram em 1934, quando Lange ministrou conferência no Rio de Janeiro. Cesar Buscacio reproduz duas fotografias daquele momento - uma delas mostrando os dois estudiosos ao lado de Luiz Heitor Corrêa de Azevedo, Roberto Tavares, Francisco Albuquerque e Andrade Muricy; e a outra, com a dedicatória: "Ao Curt Lange homenagem de Mário de Andrade - São Paulo - 1934"”. O autor da dedicatória era escritor de renome e poderia auxiliar com o Boletín Latino-Americano de Música para o qual Curt Lange buscava colaboradores. A 28 de abril de 1934, ao anunciar que começava as tratativas para fazer novo número do Boletín, solicitou aproximá-lo dos compositores Souza Lima,

6 LANGE, Francisco Curt [Carta] 20 nov. 1932, Montevidéu, URU. [para] Mário de Andrade. São Paulo. 2 folhas. Instituto de Estudos Brasileiros, Universidade de São Paulo. A localização se aplica às demais cartas de Curt Lange para o escritor.

7 BUSCACIO, C., op. cit., p. $3_{1}$ e 216 , respectivamente. 
Francisco Mignone e "los que tienen condiciones para escribir algún artículo". Mário parece ter se esquivado da função ao colocar:

Ademais é preciso que você compreenda a minha posição aqui em São Paulo, onde não tenho prestígio algum ${ }^{9}$. A minha posição de crítico que jamais respeitou a alguém e severíssimo, me obrigou a tomar uma posição de isolamento enorme. (...) E a minha posição de "modernista" como chamam, ainda me separou mais do meio ambiente..$^{10}$

Mas, quando o Boletín ficou pronto, o crítico brasileiro não poupou elogios ao trabalho e escreveu entusiasmado:

Recebi o Boletim que está simplesmente admirável. É (...) extraordinário o trabalho que você teve para organizar tão belíssimo volume. Mas creia que seu esforço foi perfeitamente compensado, pois realmente não existe em toda América, obra musical tão importante, tão uniforme, tão bem concebida e colaborada como o Boletim. Fiquei entusiasmadíssimo, e tenho feito parte desse entusiasmo a quantos me cercam. Desgraçadamente não tenho nem jornal nem tempo suficiente para dizer todo o bem que penso do seu admirável Boletim. ${ }^{11}$

Pouco tempo depois Lange seria procurado por Mário de Andrade que buscava informações para a fundação e organização da Discoteca do Departamento de Cultura.

A título de ilustração de como era tanto moderna quanto laboriosa a organização documentária e física de material sonoro, àquela época, transcrevemos trecho de carta de Curt Lange ao brasileiro, em agosto de 1935:

Meu fichário capital, ou seja, o de maior importância, no qual se encontram fichadas por ordem alfabética e por autores, se fez em livros de fechos automáticos, tipo "Flex-Site", norte-americanos. Estes livros têm que estar nessa, ou em qualquer dessas casas de

8 LANGE, Francisco Curt [Carta] 28 abr. 1934, Montevidéu, URU. [para] Mário de Andrade. São Paulo. ı folha.

9 Mário de Andrade ainda não era diretor do Departamento de Cultura, cargo que só iria ocupar no ano seguinte.

10 Apud BUSCACIO,C., op. cit., p. 215. Carta de 7 nov. 1934.

11 Idem. Carta de 3 ago. 1935. 
artigos de escritório, de máquinas de escrever etc. Recomendo-lhe que já trate de vê-los. São de muito fácil manejo e recomendo-lhe que nunca trate de comprar o fichário tipo armário. São antiestéticos e, além do mais, de difícil manejo. Já os livros "Flex-Site", podem-se levá-los debaixo do braço a qualquer parte, inclusive à sua casa. Além disso, são inerrompíveis (?) e de uma duração eterna. Há várias medidas, eu recomendo-lhe o tipo mediano, do qual lhe remeterei as medidas exatas. ${ }^{12}$

E o minucioso musicólogo alemão aconselha ao colega de São Paulo que vá averiguando os preços desses livros metálicos que, mesmo relativamente caros, compensariam por seu manejo prático. Lange usava 15 desses livros com resultados satisfatórios. Quando Lange esteve no Brasil, deixou material de interesse sobre o funcionamento de discotecas e, pela carta de 15 de agosto de 1935, podemos saber que Luiz Heitor Corrêa de Azevedo, da Escola Nacional de Música do Rio de Janeiro, já solicitara material para a mesma finalidade. Tendo adquirido larga experiência trabalhando no Servicio Oficial de Difusión Radio Eléctrica (Sodre), ele era um crítico severo ao alertar:

No existen discotecas en la América Latina, o mejor dicho, no existe ninguna que tenga organización suficiente como para que le recomiende la adaptación del sistema. La que posee el Dr Roquette Pinto en el Departamento de Educação en Rio, también tiene sus defectos, a mi manera de veer..$^{15}$

Chegado o mês de outubro, Curt Lange envia um exemplar da revista Educación, pois trazia "elementos ilustrativos" a respeito da instalação das discotecas ${ }^{14}$. Imerso no preparo de outra edição do Boletín, o musicólogo estava cada vez mais decepcionado com a receptividade dada à sua iniciativa. Em junho de 1937, Mário de Andrade já era diretor do Departamento de Cultura quando recebeu notícias sobre o andamento do periódico n. 4 que, aliás, viria a ser publicado em Bogotá. Lange lamentava que desde 1934 as relações entre ele e o Brasil tivessem esfriado tanto. Mário de Andrade chegou a planejar apoio financeiro

12 LANGE, Francisco Curt [Carta] 15 ago. 1935, Montevidéu, URU. [para] Mário de Andrade. São Paulo. 1 folha.

13 Idem, ibidem.

14 Idem. 11 out. 1935, Montevidéu, URU. [para] Mário de Andrade. São Paulo. 1 folha. 
para a publicação, requisitando ao setor responsável, ou seja, a Sérgio Milliet $^{15}$.

Analisando a correspondência de Camargo Guarnieri e Curt Lange, Cesar Buscacio reproduz trechos esclarecedores acerca de um estremecimento entre os musicólogos do Uruguai e do Brasil, decorrência de uma defesa inflamada do último a favor de obra de Lorenzo Fernandez, que teria sido criticada. Guarnieri assegurou que da parte do brasileiro estava tudo resolvido, ele não queria mal a Curt Lange e aguardava uma carta. Mas o musicólogo teuto-uruguaio estava muito ferido: "Le agradezco sus buenos oficios ante Mário de Andrade. También yo le estimo mucho, pero yo, en cambio, nunca he escrito ni escribiré jamás una cosa sobre él, como él lo hizo sobre mí"16. A situação parece não ter se normalizado com facilidade, porque, em 1941, Guarnieri foi solicitado para mediar um pedido de Curt Lange ao ex-diretor do Departamento de Cultura de São Paulo a favor do idealizado Instituto Uruguaio-Brasileiro de Cultura. Apesar disso, Buscacio reproduz outro trecho de carta enviado de São Paulo, em fevereiro do ano seguinte atestando que as relações entre os dois musicólogos "mantiveram um caráter bastante amistoso"17. Em 18 de maio de 1944, Mário de Andrade escreveria o artigo “Número especial”, publicado em Mundo Musical, coluna assinada pelo crítico, na Folha da Manhã, no qual trata da divulgação do Boletín Latino-Americano de Música cuja abordagem seria a música brasileira e que, segundo observações de Jorge Coli ${ }^{18}$, só seria publicado em 1946, depois da morte do escritor e musicólogo paulista. Ainda nas palavras de Jorge Coli: "Francisco Curt Lange iria ali lhe dedicar [a Mário] uma comovida e lúcida homenagem: nele [no Boletín de 1946] sairiam 'As danças dramáticas do Brasil""19.

Faz sentido, nesse contexto, avaliar o que escreve Remião a respeito do artigo da Folha da Manhã, de $1944^{20}$. O autor observa que Mário de

15 Idem. o6 jun. 1937, Montevidéu, URU. [para] Mário de Andrade. São Paulo. 1 folha. Nota a lápis vermelho: "Mostrar Sergio e combinar possível auxílio".

16 Apud BUSCACIO, C., op. cit., p. 217. Cartas datadas de 11 e 16 out. de 1940.

17 Idem, ibidem, p. 216 e 217.

18 COLI, Jorge. Música final: Mário de Andrade e sua coluna jornalística Mundo Musical. Campinas: Ed. da Unicamp, 1998. p. $3^{61 .}$

19 Idem, ibidem, p. 150. Nesse artigo, Mário de Andrade afirmava que quem se interessasse pela música em São Paulo não podia ignorar quem fosse Curt Lange. E, para acompanhar os trabalhos do musicólogo estrangeiro, no preparo do próximo número do Boletín em questão, foi nomeada uma comissão formada por músicos brasileiros consagrados.

20 REMIÃO, Cláudio Roberto Dornelles. O Mário de Andrade de "Número especial". In: XXIV Simpósio Nacional de História, 2007, São Leopoldo. História e multidisci- 
Andrade recusou-se a fazer parte da equipe que auxiliou Lange, justificando que considerava ofensivo ao musicólogo que interferissem em seu trabalho. O teuto-uruguaio vai encontrar registros musicais em Minas Gerais, partituras do final do século XVIII, apesar de Mário de Andrade achar que uma árdua pesquisa poderia resultar improfícua ${ }^{21}$. Tal não se deu, porque Lange encontrou muitas coisas, além do já conhecido José Maurício.

Mário de Andrade e Lange encontraram-se num hotel em Belo Horizonte, em 1944; segundo Remião, o primeiro não escreveu nada sobre a pesquisa do colega, que ainda estava no início - o musicólogo do Uruguai encontrara, até então, partituras do século XIX. Remião aponta dois motivos: Mário não se motivava por aquelas composições do período colonial porque não tinham feições nacionais ou porque o período até sua morte teria sido escasso para isso. Lembremos que o autor de Macunaíma, nessa época, já havia pesquisado o trabalho de Jesuíno do Monte Carmelo $^{22}$, descobrindo um compositor e artista plástico do século XIX, em pesquisa de levantamento de fonte primária para SPHAN, para o qual trabalhava. Talvez Mário de Andrade achasse que o seu dever fosse fazer o que tinha feito: escrevera um artigo que incitava os pesquisadores brasileiros da área de música a participarem do sexto Boletín Latino-Americano de Música. Ou porque também considerasse que a pesquisa de Lange ainda estivesse muito no início...

Associando isso ao que escreve Buscacio, em sua tese Americanismo e nacionalismo musicais na correspondência de Curt Lange e Camargo Guarnieri (1934-1956), quando menciona os achados de Lange, em Minas Gerais, e o estado em que se encontravam partituras, pode-se pensar que Lange realizou essa viagem porque já supunha que encontraria documentos. O tema das discotecas, entretanto, não saiu da pauta da agenda de Curt Lange. Tanto é assim que, em carta de 14 de dezembro de 1944, regressando de uma viagem que fizera ao Nordeste do Brasil, afirmou categoricamente ter fundado três discotecas públicas municipais nos três estados que visitou, criadas com as funções de "reeducação musical do público e gravação de manifestações folclóricas”.

Deixei virtualmente fundadas nos três estados que visitei, três Discotecas Públicas Municipais, com dois funcionários: reeducação

plinaridade: território e deslocamentos: anais do XXIV Simpósio.

21 Informação do artigo "Número especial". Folha da Manhã , 18 maio 1944.

22 Pintor, arquiteto, entalhador - mas também músico (compunha música sacra) e poeta do período colonial, nascido em Santos, em 1764, trabalhou como artista em Itu, onde morreu, em i819. 
musical do público e gravação de manifestações folclóricas, ambas com a direção de pessoas competentes e a supervisão de pessoas especializadas. Espero voltar em Janeiro a Minas Gerais e tenho desejos de fundar também ali uma Discoteca Pública, com ajuda de Menegale e Bosmans. Os Estados estão sofrendo uma desnutrição pelo centralismo da capital federal e a nefasta radiodifusão, não controlada pelo Estado. Falei com crueza em todos os pontos e assinalei os graves erros em que se ocorre. Bahia está musicalmente morta e no sentido intelectual mostra um debilitamento que se percebe rapidamente ${ }^{23}$.

Aliás, fazendo planos de regressar ao país, esperava fundar a quarta instituição do gênero, só que em Belo Horizonte (Minas Gerais).

\section{Relações musicais entre o Brasil e os Estados Unidos}

No rastro das pesquisas de Mário de Andrade, podemos encontrar no periódico The Musical Quarterly, assinado pelo modernista, significativas fontes de informação que embasaram a constituição do juízo do estudioso sobre a música norte-americana. Nos escritos, o estudioso paulista tomou ciência de canções folclóricas de povos primitivos que ocupavam os Estados Unidos e até manifestações musicais e danças folclóricas do Havaí ${ }^{24}$. Significativos da época em questão são dois artigos de 1938 - um de Winthrop S. Boggs: "Music and Stamps", sobre músicas que inspiraram desenhos de selos postais - ligado diretamente à valorização das nações e suas honrarias, e o outro, de Marian Hannah Winter, "American Theatrical Dancing from 1750 to 1800", que confirma o caráter coletivizador e socializante da música para teatro dos Estados Unidos - e que Oneyda Alvarenga exibirá na prática em Concertos de Discos, no auditório da Discoteca Pública de São Paulo. Há ainda artigos sobre

23 LANGE, Francisco Curt [Carta] 14 dez. 1944, Montevidéu, URU. [para] Mário de Andrade. São Paulo. 1 folha.

24. Ao mesmo tempo que os Estados Unidos procuravam conhecer até a exaustão as fontes musicais de seus domínios, pretendiam impor sua cultura a outros povos. Aludindo a esse fato, Mário de Andrade escreve: "Hoje a Federação [Nacional dos Clubes Musicais] estende seus tentáculos culturais até o Alaska, as Filipinas e Hawai, a toda parte da nação mandando em intercâmbio as suas orquestras, as suas massas de coros e os compositores nacionais”. ANDRADE, Mário de. A expressão musical dos Estados Unidos. Rio de Janeiro: Leuzinger, 1941. p. 23 (Lições da Vida Americana, 3). 
compositores norte-americanos da atualidade, como Leo Sowerby ou Copland $^{25}$, entre outros ${ }^{26}$. E, para que não nos esqueçamos que os Estados Unidos também mantinham interesse na música sul-americana, vale citar o artigo de Rosenfeld ${ }^{27}$ intitulado "Szymanowski - Villa-Lobos". Do compositor polonês, passa o foco para Villa-Lobos: "Another cup-, libation-, wine-bearer was our good friend the United States of Brazil”. Fazia, evidentemente, parte da política da boa vizinhança.

Abordando a origem da música norte-americana, em seu trabalho A expressão musical dos Estados Unidos ${ }^{28}$, Mário de Andrade aponta a presença da polifonia puritana nos cantos religiosos, de caráter coletivo. E os negros da América do Norte que cantavam nas plantações e nos rituais cristãos, criaram o jazz. A respeito do caráter polifônico e "democrático" do jazz, o musicólogo escreve que: "a música americana é um milagre de compreensão divinatória da vida" ${ }^{2}$. Nessa realidade atual, "quase nada se fez, em música, que não fosse pelo processo associativo" ${ }^{0}$. Em suas conclusões sobre a nacionalização da música dos Estados Unidos, o autor lembra que a presença de elementos urbanos, de Arranha-céus (Carpenter) e Um americano em Paris (Gershwin) não são menos "nacionais" do que músicas contemporâneas de velhos países europeus, onde o traço da música vinda do solo primitivo já foi incorporado à composição erudita nacional de maneira bem resolvida. E chega a questionar se o internacionalismo da música norte-americana não seria o lado mais humano e feliz do cosmopolitismo ${ }^{31}$. Ao chamar a atenção para a "grande lição histórica da arte musical dos Estados Unidos”, Mário se referia à "força social" dessa arte, que seria a base para a função social das discotecas - a divulgação do conhecimento musical. O estudioso conclui que essa força da música nos Estados Unidos viria da sistematização de seus

25 The Musical Quarterly, Nova Iorque, 3, p.372, 1938.

26 O último artigo do primeiro n., do ano de 1940, é escrito por Ashley Pettis e se trata de um fórum de composição norte-americana, realizado em 1935. WPA (Works Progress Administration) foi uma agência do New Deal, programa que foi concebido para combater o desemprego e, ao mesmo tempo, estimular a economia. Durante os anos da Depressão, a WPA foi um dos maiores empregadores dos Estados Unidos, e os trabalhos da WPA podem ser vistos em cada estado norte-americano hoje. Como qualquer programa de bem-estar social importante, a WPA teve sua cota de críticas e problemas, mas também foi saudada como uma organização extremamente útil e produtiva.

27 The Musical Quarterly, Nova Iorque, 4, p. 513-8, 1939.

28 ANDRADE, Mário de. A expressão musical dos Estados Unidos. Op. cit., p.26.

29 Idem, ibidem, p.12.

zo Idem, ibidem, p.18.

31 Idem, ibidem, p.19. 
primórdios corais religiosos ${ }^{32}$. Falando da vaidade nacional dos Estados Unidos, "inigualável entre os povos contemporâneos", Mário escreve:

Hoje os Estados Unidos têm a sua semana da música nacional (...) como [ainda] de música pan-americana, preocupados da cooperação musical com esta América do Sul, como o provou a (...) Conferência sobre Relações Musicais Interamericanas, realizada em Washington, em outubro do ano passado ${ }^{33}$ (...) aliás, só havia norte-americanos e o pensamento norte-americano, com mais apenas a voz desse admirável sonhador e realizador que é o musicólogo Curt Lange. Os países sul-americanos não foram ouvidos, embora eu não tenha forças (...) para condenar essa atitude de pan-americanismo solitário (...) Ainda recentemente, (...) o nova-iorquino Carleton Smith, embora fazendo um estudo de egoística incompreensão, muito chewingunizado, sobre a situação musical sul-americana, tinha (...) esta observação dolorosa mas profunda em relação a todos nós: "Muitas vezes (...) tenho a impressão de que nós, norte-americanos (...) sentimos mais profundamente do que os sul-americanos". Este sentir "como coletividade" é o que apresenta o panorama da música norte-americana. ${ }^{34}$

E frisa a vulgarização da hora da radiodifusão educativa ${ }^{35}$, a criação ianque dos meios de mecanismos da socialização e da educação musicais do povo norte-americano ("panorama incomparável de musicalização social de um povo"), quando descreve o incentivo que se dá ao grande público. Assim, quando toca no assunto das discotecas:

Nas bibliotecas (...) há sempre uma discoteca anexa, com serviço circulante dos (...) discos; sem contar as discotecas de serviço

32 ANDRADE, Mário de. A expressão musical dos Estados Unidos. Op, cit., p 21.

33 Refere-se a 1939. "A expressão musical dos Estados Unidos”, conferência de Mário de Andrade, foi realizada no auditório da Associação Brasileira de Imprensa, no dia 12 de dezembro de 1940 e publicada depois - a publicação também é de 1940. Em carta de 18 de abril de 1941, Sprague Smith escreve para agradecer e elogiar esse "pequeno" estudo.

34. ANDRADE, Mário de. op. cit., p. 21-22.

35 Em carta de 18 de abril de 1941, Smith envia folhas mimeografadas que descrevem o programa de música da Rádio-Escola das Américas da Colúmbia Broadcasting System para 1941-1942. A partir de 8 de outubro, essa Rádio iria fazer uma série de transmissões de interesse para os americanos. Nos programas, apresentariam músicas das Américas do Norte e do Sul, canções nas três línguas do continente. O norte-americano queria que Mário de Andrade enviasse canções populares de caçadores, mineiros e gente da montanha. 
científico especializado, como a de Washington, que já superou em riqueza o Phonogramm Archiv de Berlim, conta (...) para mais de 50 mil fonogramas de raças primitivas ou folclóricas do mundo (...). Por meio do fonógrafo e dos discos distribuídos gratuitamente, uma instituição já conseguiu aumentar de mais de $50 \%$ a frequência espontânea a concertos, numa cidade de tipo médio. ${ }^{36}$

O autor deixa clara a função social dessas instituições: as discotecas seriam o celeiro do material sonoro e, àquela época, também a plataforma de gravação de registros a serem preservados e estudados.

Vê-se que esse conceito de "reeducação e gravação" norteava tanto Curt Lange e Sprague Smith quanto Mário de Andrade. Os três musicólogos idealizavam e criavam acervos sonoros em seus países, pautando-se pelos conceitos de rádios educativas dos países europeus, como dos próprios Estados Unidos - os dois primeiros por sua vivência e o terceiro, a partir de leituras, já que desde a década de 1920 assinava periódicos europeus sobre o assunto: a discoteca como detentora da preservação da manifestação musical folclórica e nacional.

Em outubro de 1939, uma conferência organizada pelo Departamento do Estado de Washington reuniu políticos e livres pensadores em torno da música latino-americana sob os auspícios da Biblioteca do Congresso. Segundo Leila Fern ${ }^{37}$, um comitê ficou encarregado de organizar um centro de música interamericano sediado na Pan American Union. Com verba arrecadada para o funcionamento dos cinco primeiros anos, o centro ficou sob a direção de Charles Seeger e o primeiro programa de ação ficou pronto em 1941 com a colaboração de Sprague Smith. Ele escreveu dez cartas para Mário de Andrade, entre julho de 1940 e junho de 1944, enviadas de São Paulo, Rio de Janeiro e Nova Iorque. Tratam de questões pertinentes ao trabalho, com exceção da última delas, espécie de noticiário de última hora, uma carta pândega demonstrando grande proximidade entre eles, onde estão envolvidos amigos comuns do meio musical. Chefe da Divisão de Música na New York Public Library desde 1931, Smith tinha familiaridade com o assunto das discotecas o que faz supor que com a presença dele entre nós tenha se estabelecido uma rede de influências mútuas de reflexão, ponto que aqui interessa analisar. Musicólogo e adido cultural dos Estados Unidos, flautista, estudioso da

36 ANDRADE, Mário de. A expressão musical dos Estados Unidos. Op. cit., p 23.

37 FERN, Leila. Origin and Functions of the Inter-American Music Center. Notes, Music Library Association, Second Series, vol. 1, n. 1, dez. 1943, p. 14-22. Disponível em: <http://www.jstor.org/stable/889859>. Acesso em: 25 out. 2013. 
literatura francesa e espanhola, Sprague Smith já enfatizava a importância da formação dos acervos musicais, em papel ou registros sonoros, sendo um entusiasta das bibliotecas e discotecas. Entre os brasileiros com os quais manteve estreita colaboração de trabalho e amizade importa destacar o também musicólogo Luiz Heitor Corrêa de Azevedo que escreveu a respeito do amigo. Segundo ele, Sprague Smith representava “(...) the pure essence of qualities of the East Coast, New England, Harvard man. The embodiment of religious (Christian) and civic values (liberty and democracy) (...) and an attachment to European culture" ${ }^{\circ 8}$. Na década de 1940, na presidência de Roosevelt, quando os Estados Unidos angariavam a solidariedade internacional, ele era o adido cultural apropriado para amalgamar as várias tendências e naturezas políticas dos debates, por meio da música.

Ao que parece, a aproximação entre Sprague Smith e Mário de Andrade foi imediata porque do Rio de Janeiro ele orquestrou em detalhes a visita que o norte-americano faria à Discoteca do Departamento de Cultura, orientando a amiga Oneyda Alvarenga, chefe da instituição. Apresentado como diretor de Musicologia da Biblioteca Nacional de Nova Iorque, vinha em férias "ver o que é São Paulo e o que interessa a ele é o nosso São Paulo, de você, do Rubens, do Sérgio, meu, do Saia, também"39. Uma das coisas a se mostrar, caso ele quisesse, era a casa do próprio escritor modernista, "seus 10 mil volumes, seus milhares de peças musicais, correspondência, manuscritos, obras raras ou de luxo, coleção de desenhos e gravuras, marfins, peças de coleção etc." O musicólogo brasileiro sugeriu que se apresentasse a conferência sobre música norte-americana ilustrada com discos. "Eu pedia a vocês meus amigos que o juncassem de amabilidades, é um tipo humano, apesar de acreditar que democracia é ou são os USA com linchamento, racismos, Chinatown, Sacco e Vanzetti etc."

Ora, o Mário pesquisador entendia a música norte-americana e, apesar de reconhecer seus grandes méritos, mantinha sempre a vigilância crítica. Aos 12 de outubro de 1944, quando a situação da Guerra perturbava o escritor brasileiro, revoltado contra a opressão do nazismo

38 AZEVEDO, Luiz Corrêa de. Carleton Sprague Smith and Brazil. In: KATZ, Israel J. (org.). Libraries, History, Diplomacy, and the Performing Arts: Essays in Honor of Carleton Sprague Smith. Nova Iorque: Pendragon, 1991. p. 2og. (Festschrift Series, n. 9).

39 ANDRADE, Mario de. Cartas: Mario de Andrade, Oneyda Alvarenga. São Paulo: Duas Cidades, 1983. p. 240. Carta de 17 jul. 1940. Mário se referia às realizações do Departamento de Cultura nas quais contou com as colaborações e empenho de Rubens Borba de Moraes, Sergio Milliet e Luiz Saia à frente da Biblioteca, do setor de Documentação e da Missão de Pesquisas Folclóricas. 
e do fascismo, ele escreve um artigo intitulado "Música universitária", publicado na coluna Mundo Musical, da Folha da Manhã, alertando também para a dominação norte-americana:

Nós estamos sofrendo a influência incontestável dos Estados Unidos, nosso irmãozão mais rico e mais forte. Acho invencível essa influência incontestável, "são os do norte que vêm” (...). Mas cultura é discernir: há que discernir. Temos que recusar com energia a exterioridade ianque, desde a cultura em pílulas dos digestos totalitários, que não pertence à paciência nossa tropical, até certos modos de toalete e proceder, que tornam inconsolavelmente ridículos caipiras, cabeças-chatas e olhos negros. Temos que insistir na cultura europeia, especialmente na francesa; já experimentada, que nos refreia o tropicalismo, desconfiados da exabundância e das morais que nos insinuam "pocket-books", romances de 600 páginas predeterminadas e versos de perigoso e racista pan-americanismo.

Porém, Mário de Andrade pondera, equilibrando seu alerta:

Mas os Estados Unidos são milionários de coisas ótimas e influências úteis. Entre estas, aquela vida musical viva das suas universidades, jazes, improvisações deliciosas, operetas, revistas anuais. E porque não poderá por acaso um Guilherme de Almeida nos prover de uma "Ester" nossa, ou Camargo Guarnieri duma nova "Dido"? E o mérito dessa glória se repartirá entre o artista que espera e o Departamento de Cultura que o obrigou a ser grande.

\section{Uma opinião valiosa}

Tanto no âmbito dos programas de discos, em que os ouvintes podiam conhecer História da Música com a mediação de palestras (escritas pela musicóloga Oneyda Alvarenga), quanto na possibilidade de se conhecer músicas nas salas de audição, pode-se perceber a função social cumprida pelas Discotecas Públicas. Porém, se não é difícil responder qual a importância ou quais as funções delas, o mesmo não se pode dizer quanto às motivações de cada governo para criarem seus próprios acervos. Em 1938, por exemplo, Oneyda, a primeira chefe da Discoteca do Departamento de Cultura da cidade de São Paulo, justificou a importância da entidade aos leitores do jornal Diário da Noite: 
(...) a finalidade da discoteca não é divertir, não é facultar meio de matar o tempo a duas dúzias de desocupados, nem de deleitar os ouvidos de meia dúzia de amadores esclarecidos. Conhecido como deve ser de todos o papel das Artes na cultura de um povo, seu fim é colaborar para o desenvolvimento delas, fornecendo dentro da sua esfera de ação, meios de se formarem elites artísticas capazes de ilustrar a nossa vida intelectual. ${ }^{40}$

Apesar das dificuldades que Oneyda Alvarenga passou a enfrentar em sua rotina de trabalho após a saída de seu ex-professor do Departamento de Cultura, a recepção de Smith, em 1940, correu bem, mesmo porque é de se supor que o fato tenha sido explorado para impressionar Francisco Pati, diretor que assumiu a chefia do órgão:

Mário, garanto-lhe que Mr. Carleton Sprague Smith é o indivíduo que eu mais agradei em minha vida. Pulei, corri, sofri, mas creio que de falta de amabilidade minha ele não padeceu aqui. Devo ter emagrecido uns três quilos e arranjado mais dois milhões de cabelos brancos, para pôr o homem contente com a Discoteca e comigo. Parece que o consegui. Disse ao Pati que a Discoteca é mais americana, como espírito de organização, que as discotecas dos Estados Unidos (...) Mais que as palavras, que podem ser amabilidade, valem as coisas práticas: me pediu modelos das fichas folclóricas e explicação por escrito do mecanismo desse fichário; modelos dos nossos envelopes de discos; modelo dos nossos quadros de estatística. ${ }^{41}$

Sprague-Smith percebeu o esforço da diretora da Discoteca e ao escrever para Mário de Andrade, então no Rio de Janeiro, agradeceu a recepção organizada: "Ainda não estou bem certo sobre o que tenho a fazer no futuro com relação ao intercâmbio musical entre nossos respectivos países, porém sinto que o prezado amigo é a pessoa que melhor conhece a situação aqui e cuja opinião é valiosa"42. Logo foi a vez de

40 IONTA, Marilda Aparecida. As cores da amizade na escrita epistolar de Anita Malfatti, Oneyda Alvarenga, Henriquetta Lisboa e Mário de Andrade. 2004. 315 f. Tese (Doutorado em História) - Instituto de Filosofia e Ciências Humanas. Universidade Estadual de Campinas. 2004, p. 185-186.

41 AlVARENGA, Oneyda; ANDRADE, Mario de. Cartas: Mario de Andrade, Oneyda Alvarenga. Op.cit., p. 242. Carta de 27 jul. 1940.

42 SMITH, Carleton Sprague [Carta] 24 jul. 1940, São Paulo, SP BRA [para] Mário de Andrade. São Paulo. 1 folha. Desejo de travar intercâmbio musical entre Brasil e EUA. Instituto de Estudos Brasileiros, Universidade de São Paulo. A localização se aplica às demais cartas de Sprague Smith para Mário de Andrade. 
Oneyda Alvarenga receber uma carta dele, enviada de Buenos Aires. Ao dividir sua alegria com o amigo, a chefe da Discoteca reproduziu um trecho da missiva que a

tonteou (...) de contentamento: "I am still breathless from your estatistica. Nothing like it has ever been seen before, I can assure you, and I am wondering whether we could ever do something like it in America. I know that the New York Public Library, with its 50.000 visitors a year, could never handle things as completely as you do. However, it is a goal to shoot at, and I am looking forward to my return to the United States where your entire plan can be studied in detail. Probably the best thing to do is to abduct you from S Paulo by means of a scholarship." ${ }^{43}$

Sprague Smith viajava pela América do Sul para conhecer os acervos musicais, como eram mantidos e divulgados pelas instituições da Venezuela, Uruguai, Argentina, Chile, Bolívia, Equador, Peru, Colômbia e Brasil. Como representante da Biblioteca Pública de Nova Iorque, ele queria saber quais os principais autores, obras ou períodos abordados, como eram mantidos, se numa biblioteca, numa escola, numa igreja ou numa discoteca. Acervos particulares também interessavam, como os de Caracas e Montevidéu, pertencentes a Rodolph Dolge e Curt Lange, respectivamente, e havia a preocupação em localizar livreiros que pudessem fornecer obras de interesse tanto para a Biblioteca Pública na qual ele trabalhava quanto para a Biblioteca do Congresso de Washington. O resultado da análise foi publicado em Notes, periódico da Music Library Association, em documento longo e bem cuidado ${ }^{44}$. Observando cada centro visitado, ele nomeava os dirigentes das bibliotecas e arquivos nacionais, se personalidade "simpática" aos Estados Unidos. Mas, pelos nomes citados, Smith foi recebido pelos melhores interlocutores nas visitas que fez. Em Montevidéu, por exemplo, foi conhecer a coleção de Curt Lange, destinada ao Instituto Interamericano de Musicologia, e dele se reportou nos seguintes termos: "Dr. Lange is a great champion of 'americanismo musical', which means American music for the Americas and his publication, the Boletín Latino-Americano de Música is a monument of devotion to this cause" ${ }^{\prime 5}$. Visitando Recife, Salvador, Rio

43 ANDRADE, M. de, op. cit., p. 251. Carta de 23 ago. 1940.

44. SMITH, Carleton Sprague. Music Libraries in South America. Notes, vol. 11, ago. 1941, p. 19-31.

45 Idem, ibidem, p. 26. 
de Janeiro e São Paulo, foi recebido por Gilberto Freyre, em Pernambuco, Jorge Calmon de Bettencourt, Donald Pierson e Loreno Turner, na Bahia, e Rodolfo Garcia, Pedro Sinzig, Roquette Pinto e Augusto Meyer, no Rio de Janeiro. Apesar de tudo, o diagnóstico elaborado por Smith resultou desigual, uma vez que em certas capitais não havia discotecas ou centros de documentação musical especializados; excepcionalmente, ele encontrou locais classificados como verdadeiros centros culturais na medida em que integravam rádio, discoteca e orquestras. Entre as surpresas, o Sodre, do Uruguai, e a Biblioteca Nacional de Bogotá a respeito da qual elogiou: "The National Library has a music department and in this is unique among South American libraries. Phonograph records are the back-bone of the collection which in time will parallel the Discoteca in São Paulo" ${ }^{46}$.

No Brasil, a situação também era desigual. Entre as bibliotecas, arquivos musicais e discotecas estudados, Smith queria saber onde havia obras antigas, do passado colonial, quais as instituições existentes, como eram preparados os responsáveis pela catalogação. Assim, no Rio de Janeiro, visitou a Escola Nacional de Música, que contava com "uma importante coleção de música e livros", a "Biblioteca da Catedral Metropolitana do Rio de Janeiro [que] tem muitos manuscritos de música que nunca foram exaustivamente exploradas" ${ }^{47}$ e a Biblioteca Nacional, entre outros. Mas foi a Discoteca Pública de São Paulo que mereceu o melhor espaço no artigo dele: Oneyda Alvarenga sistematizara os serviços da Discoteca em 7 seções: Departamento fonográfico, Museu etnológico, Arquivo de documentos manuscritos folclóricos, Seção de cinema, Coleta de registros para uso público, Biblioteca de partituras e livros técnicos e Arquivo de matrizes. O visitante norte-americano descreveu quais os tipos de serviços prestados em cada uma das seções, ofereceu números dos diversos ítens citados - matrizes, discos, fichários - e destacou que essa era uma Discoteca a ser visitada. E ainda a Discoteca de São Paulo empreendera pesquisa de fôlego no primeiro semestre de $1938 \mathrm{em}$ iniciativa pioneira entre as instituições públicas americanas, resultando em aproximadamente 34 horas de música gravada nas regiões Norte e Nordeste do país, a Missão de Pesquisas Folclóricas. O acervo já trazia potencialmente a possibilidade de intercâmbio entre as congêneres que pretendessem constituir suas memórias musicais, ideal difundido entre todas as nações que acompanhavam o desenrolar da política mundial. O trabalho de Oneyda Alvarenga e de Mário de Andrade era movido

46 Idem, ibidem, p. $3^{0 .}$

47 Idem, ibidem, p. 22 (tradução livre) 
pela expectativa de se contar com uma rádio própria na qual o disco desempenharia papel de relevo nas estratégias didáticas e pedagógicas. Na publicação de relatório da Discoteca Pública Municipal, escrito por Oneyda em 1941 e publicado em 1942, a musicóloga informa:

Outro excelente trabalho já em realização é a troca de cópias dos nossos discos folclóricos com material da mesma espécie gravado pela Divisão de Música da Biblioteca do Congresso de Washington. Visto que a música popular norte-americana sofreu uma das influências que atuaram também na música brasileira - a influência negra -, a existência na Discoteca de material folclórico norte-americano representa um meio excelente e indispensável de estudos comparativos, necessários ao esclarecimento de muitos casos de nossa música popular. Tendo sido proposto à Discoteca, o intercâmbio demonstra (...) o interesse que as nossas pesquisas folclóricas já despertam no estrangeiro. Em 1940 esteve em nosso país o Dr. Lorenzo D. Turner, professor da Universidade de Howard (EUA), que aqui veio para estudar os elementos africanos remanescentes no português do Brasil. Interessando-se pelos nossos discos folclóricos de feitiçaria afro-brasileira, ricos de tal material linguístico, a Discoteca permitiu-lhe copiá-los, mediante a gravação de outra cópia para si mesma. Fornecemos ainda ao Dr. Turner informações que o pudessem guiar nas suas pesquisas e registros fonográficos no Nordeste e Norte brasileiros. ${ }^{48}$

De volta aos Estados Unidos, Sprague Smith pôs em marcha um plano para a aproximação dos Estados Unidos e do Brasil - provavelmente já discutira alguns aspectos e possibilidades de trabalho com Mário de Andrade, tais como nomes e instituições e as formas de colaboração. Porque, de Nova Iorque, Smith escreveu, reproduzindo provérbio da sabedoria popular: "Você poderá me julgar um mau caçador pois atirei no que vi e matei o que não vi"49. Meses depois o projeto teve continuidade, quando ele anunciou a visita de Copland ao Rio de Janeiro, com data marcada para a chegada a 22 de outubro de 1941. Além de sugerir ao colega brasileiro alguns temas de conferências ilustradas para que o compositor apresentasse em castelhano para o público de São Paulo, Carleton queria saber se haveria a possibilidade de organizar algum

48 ALVAREnga, Oneyda. A discoteca pública municipal. São Paulo: Departamento de Cultura, 1942. Separata da Revista do Arquivo, n. LXXXVII. p. 16.

49 SMITH, Carleton Sprague [Carta] zo dez. 1940, Nova Iorque, EUA. [para] Mário de Andrade. Rio de Janeiro. 1 folha. 
concerto para que Copland ${ }^{50}$ tocasse ou regesse e, para tanto, forneceu alguns títulos de obras: "Suíte" do Ballet Billy the Kid,"Quiet Cit" ou "El Salón México" a "Sinfonia n. 2" de Randhal Thompson, o "Concerto para violino" de Samuel Barber, entre outros. Ao longo do tempo, a qualidade da relação entre Mário de Andrade e Sprague Smith alterou-se sensivelmente e este viu no amigo brasileiro um interlocutor à altura quando confessou:

Desejo (...) conhecer o verdadeiro espírito brasileiro e interpretar meu país àqueles que por ele se interessam. (...) para haver um sadio entendimento entre nações, é preciso falar menos em canhões, aeroplanos e navios e pensar mais em ideias, sons e cores. Esse entendimento deve ser atingido sobre bases intelectuais de uma mesma filosofia. ${ }^{51}$

Agora eles partilhavam vários temas de interesse e, morando os dois no Brasil, encontravam situações para conversar tanto em São Paulo quanto no Rio de Janeiro. Pode-se aferir o grau de entrosamento entre eles quando, em 1943, Smith escreveu para o amigo: "Gosto muito da sua frase: 'O livro não é apenas uma dádiva à compreensão: é e deve ser principalmente um fenômeno de cultura' e usei-a, aliás, em minha conferência de ontem à noite sobre a Biblioteca Pública de Nova Iorque"52. Poucos dias após, do Rio de Janeiro, enviou um texto sobre arte colonial norte-americana, elogiou a obra escultórica de Aleijadinho e cogitou de conversarem sobre os estilos coloniais, tanto dos Estados Unidos quanto do Brasil. Na despedida, caçoou de si mesmo e de Mário de Andrade: "Ser um acentuado puritano é muito diferente do misticismo católico"53.

5o Oneyda não só se embasou na obra de Copland para escrever o último capítulo ("Como ouvir música") de seu livro inédito (A linguagem musical), como ainda reservou parte de um concerto de discos a esse compositor, em junho de 1942 - o compositor visitara o Brasil em 194.1. Copland escreveu música para teatro sobre argumentos da problemática social da época da depressão, nos Estados Unidos. Então, é fácil relacionar o enfoque de Oneyda Alvarenga, nessa audição: a diretora da Discoteca, em entrevistas a jornais, falando a respeito da oposição da ópera à capacidade de socialização da música, menciona a música para teatro, como veículo da socialização - e dentro da política de boa vizinhança, a vinda de Copland fazia parte de projeto de aproximação com os Estados Unidos, idealizado e mediado por Sprague Smith, quando em contato com Mário de Andrade.

51 SMITH, Carleton Sprague [Carta] 19 mar. 1943, Nova Iorque, EUA. [para] Mário de Andrade. São Paulo. 1 folha.

52 SMITH, Carleton Sprague [Carta] o6 nov. 1943, Nova Iorque, EUA. [para] Mário de Andrade. São Paulo. 1 folha.

53 SMITH, Carleton Sprague [Carta] 10 dez. 1943, Rio de Janeiro, RJ BR A. [para] Mário de Andrade. São Paulo. 1 folha. 


\section{Pedidos, pedidos, pedidos ${ }^{54}$}

Em cartas trocadas entre Mário de Andrade, então morando no Rio de Janeiro, e Oneyda Alvarenga, no período entre 1939 e 1940, há referências constantes aos interesses de autoridades norte-americanas no material fonográfico folclórico coletado pela Missão de Pesquisas Folclóricas, do Departamento de Cultura de São Paulo, nas regiões Norte e Nordeste do Brasil. Em 1939, Oneyda Alvarenga já menciona ${ }^{55}$ o interesse de Henry McGeorge, da Biblioteca do Congresso, no intercâmbio de material folclórico da Discoteca Municipal e fala que explicou a ele que seria difícil, em função da falta de matrizes e estudo das peças. Henry McGeorge cogitou da possibilidade da intervenção do Ministério das Relações Exteriores no caso. Em carta de Oneyda a Mário de Andrade ${ }^{56}$, o texto menciona uma conferência de Harold Spivacke, chefe da Divisão de Música da Biblioteca do Congresso, que Oneyda assistiu com fito nas técnicas. O interesse não era só na direção Estados Unidos-Brasil: a diretora da Discoteca Pública de São Paulo atentou para o uso técnico do material sonoro e escreveu a Spivacke perguntando como estudavam os discos de alumínio revestidos de acetato e como o dispunham ao público sem que o material se estragasse. Com isso, Spivacke manifestou seu interesse em fazer intercâmbio de material com a Discoteca Pública Municipal.

O ex-professor de Oneyda Alvarenga responde ${ }^{57}$ que esta deve falar com Pati. Em todo caso, a musicóloga analisaria a discografia de Spivacke, para eleger o que seria trocado, no caso de "peça por peça" consultando sempre Mário de Andrade que, mais adiante, escreveria ${ }^{59}$ um item significativo à diretora da Discoteca: "Caso Spivacke. (...) Não só ele quer vender ou distribuir as cópias dos discos para instituições culturais, mas divulgá-los o mais possível, até para os indivíduos avulsos".

54 ANDRADE, Mario de. Cartas: Mario de Andrade, Oneyda Alvarenga. São Paulo: Duas Cidades, 1983. p. 240. Carta de 17 jul. 1940. Mário de Andrade começando assim sua carta, prepara Oneyda para atender solicitações de norte-americanos, pedidos referentes a consultas aos fonogramas da Discoteca.

55 ANDRADE, Mario de. Cartas: Mario de Andrade, Oneyda Alvarenga. São Paulo: Duas Cidades, 1983. p.187. Carta de zo maio 1939.

56 Idem, ibidem. p. 2o2. Carta de 20 out. 1939.

57 Idem, ibidem. p. 205. Carta de 27 out. 1939.

58 Idem, ibidem. p. 24,o. Carta de 17 de jul. 1940.

59 Idem, ibidem. p. 2o6. Carta de 12 de abr. 1940. 
Citando o próprio Spivacke, ele menciona os pontos de distribuição e divulgação do material sonoro: "universities, libraries and individuals will be... etc."

Que livrarias são essas? (...) de compra e venda? E indivíduos quaisquer, amadores(...)? E “disseminar pro público geral” significa (...) irradiações? (...) um amador ianque ou turco comprará essas peças inéditas brasileiras na A. do Norte, e aqui ninguém as pode adquirir! Eu não as posso ter no Brasil e um não folclorista (...) os terá não para estudo mas pra divertir as americaninhas que passem o domingo com ele na sua casa de campo!

E considerando absurdo, o ex-diretor do Departamento de Cultura recomenda a Oneyda que só faça essa concessão se o prefeito (Prestes Maia) autorizasse. Se os interesses da musicóloga nos conhecimentos e no material de Spivacke eram de ordem técnica, pelo menos de início, os de Mário se focalizavam diretamente no conteúdo: "Quanto ao que você escolher, pergunte (...) o que ele tem de negros da África; de Portugal; de Cuba; de ameríndios; e de negros africanos de origem, já nos Estados Unidos". E acrescenta: "E o fato dele não ter fotos, filmes, instrumentos e toda a documentação musical anexa ao documento musical, prova que a nossa Discoteca foi mais cientificamente concebida que a dele... Viva nós, minha cara".

Mas isso não sem antes recomendar que Oneyda deixasse claro a Spivacke que os fonogramas eram "nossos"; e que o norte-americano "que mandasse" discos virgens, para que a troca fosse razoável e ele não "ganhasse" no número da documentação. Logo Oneyda acalma os nervos de Mário, quando esclarece: "(Você confundiu libraries com livrarias)" E o público geral era o de "universidades, bibliotecas e indivíduos". E explica também a seu interlocutor que o material só não poderia ser usado comercialmente. A Discoteca de São Paulo também pediu cópias para si própria. Depois de tudo acertado, uma carta Oneyda informa ao escritor $^{61}$ sobre a visita de Lorenzo Turner, estudioso norte-americano de línguas africanas e que buscaria fonogramas de música folclórica brasileira com o intuito de decodificar influências africanas na língua do povo. Turner também desejava fazer cópias e segue-se uma série de empecilhos. Oneyda avisou que seria impossível. Turner propõe fazer

6o AlVArenga, Oneyda; ANDRADE, Mario de. Cartas: Mario de Andrade, Oneyda Alvarenga. Op.cit., p. 226. Carta de zo abr. 1940. p. 226.

61 Idem, ibidem. p. 238-9. Carta de 13 jul. 194 o. 
duas cópias de cada vez, porque seu aparelho dispunha de dois pratos - uma das cópias seria da Discoteca de São Paulo. Mas Oneyda temia que o material fosse usado largamente fora do Brasil - sendo que os próprios estudiosos do país não podiam fazê-lo. Porém, Oneyda ponderava que, apesar de ser difícil confiar na sinceridade de especialistas como Spivacke e Turner, levado o material para outro país, não se podia mais fazer controle algum. Mas ela poderia, por sua vez, propor a Turner utilizar só o texto, porque o interesse desse pesquisador era puramente linguístico - não musical. Por fim, depois de muitas objeções por parte de Mário de Andrade, Turner aceita que Antônio Ladeira leve os discos até o Rio de Janeiro, onde fizeram as gravações.

\section{Conclusões}

Nesta abordagem do tema, as fontes foram bem delimitadas com o intuito de equilibrar dados díspares, pois embora Sprague Smith e Curt Lange tenham tido formações acadêmicas até certo ponto semelhantes, pertenciam a culturas muito distintas. No centro desse embate, Mario de Andrade também foi apresentado de forma bastante parcial frente ao intelectual que foi e o papel que assumiu na vida cultural brasileira. A análise panorâmica da correspondência dos três musicólogos, no entanto, permite demonstrar que o poder político do musicólogo e escritor brasileiro aumentou sobremaneira após a experiência à frente do Departamento de Cultura. Eis porque, entre outros motivos, ele foi chamado para atuar no Rio de Janeiro onde antigamente se instalava a capita federal.

Também parece claro que a consulta às correspondências recíprocas permitindo o acesso ao conteúdo das cartas do intelectual brasileiro poderá iluminar fatos que ainda são obscuros. Mas mesmo que se considere este ponto e o fato de que a correspondência de Curt Lange é bem mais numerosa do que a de Sprague Smith, não é temerário afirmar que ao se confrontar o envolvimento de cada um deles com a cultura brasileira, a participação de Mario de Andrade foi muito maior no projeto aberto para o diálogo trazido pelo adido cultural dos Estados Unidos. 


\section{Sobre as autoras:}

\section{Flávia Camargo Toni}

Professora Titular do Instituto de Estudos Brasileiros (IEB) da USP. Mestre e doutora em Artes e livre-docente pela USP. Pesquisadora no IEB, onde é a Presidente e Coordenadora do Programa Culturas e Identidades Brasileiras. Bolsista de Produtividade em Pesquisa do CNPq - Nível 2.

E-mail: flictis@usp.br

\section{Valquíria Maroti Carozze}

Mestre em Filosofia pela Universidade de São Paulo (USP), pelo Programa de PósGraduação Multidisciplinar em Culturas e Identidades Brasileiras, dentro da linha de pesquisa Brasil: a Realidade da Criação, a Criação da Realidade, do Instituto de Estudos Brasileiros (IEB).

E-mail: valquiriamaroti@hotmail.com 